\title{
Cyclone Phase of Tropical Cyclones Landfalling in Japan during 2004-2006
}

\author{
Naoko Kitabatake and Kotaro Bessho \\ Meteorological Research Institute, Tsukuba, Japan
}

\begin{abstract}
Cyclone phases for 15 tropical cyclones (TCs) that made 17 landfalls in Japan during 2004-2006 are examined by using the gridded reanalysis datasets of the Japan Meteorological Agency. TCs with 9 landfalls south of $40^{\circ} \mathrm{N}$ from late June through early September had the structure of typical tropical cyclones, i.e., a thermally symmetric warm-core structure. TCs of 3 landfallings north of $40^{\circ} \mathrm{N}$ and one landfalling in western Japan in mid-June had the structure of a frontal cyclone, which suggests that the environmental baroclinicity would have contributed to the structure change of the cyclones. With the other 4 landfalls south of $40^{\circ} \mathrm{N}$ after mid-September, TCs were transitioning into extratropical cyclones with a thermally asymmetric warmcore structure, and were associated with significant features including frontal heavy rainfall and localized gusts related to the environmental baroclinicity. This suggests that precautions should be taken against a TC approaching Japan in mid- and late autumn associated with features different from those of a typical TC.
\end{abstract}

\section{Introduction}

A tropical cyclone (TC) generated in the tropical or subtropical latitude of the western North Pacific sometimes approaches Japan and causes significant damages. It has been empirically known in Japan that a TC is sometimes associated with strong winds near its center as a typical mature TC, but it is sometimes associated with heavy rainfall along preexisting frontal zones. The interaction between a TC and a midlatitude front causes a structural change of the TC into an extratropical (frontal) cyclone, i.e., the extratropical transition (ET), which often occurs near Japan (e.g., Muramatsu 1985; Klein et al. 2000). However, the variety of the TC structure and the associated features (e.g., wind and rainfall distribution) is still needed to be clarified for disaster prevention and mitigation.

Ten TCs made landfall in the main islands of Japan in 2004, where the average number is 2.6 per year. Typhoon Research Department/ Meteorological Research Institute (2006) and Japan Meteorological Agency (2006) (hereafter MRI06 and JMA06, respectively) documented the evolutions of the 10 landfalling TCs, emphasizing the variety of their structure and the associated features, e.g., strong winds associated with Typhoon (TY) Songda (0418: The TC number is defined by the JMA in the manner that "0418" means the 18th named TC in the western North Pacific basin in 2004), northerly gusts associated with TY Ma-on (0422), and floods due to heavy rain related to TY Tokage (0423). Also in the following two years some TCs caused great damage to Japan. Therefore we examine 17 landfall cases of 15 TCs during 2004-2006 (Fig. 1a) in this study, focusing cyclone phase transition that can be presented in the phase diagram proposed by Hart (2003) and Evans and Hart (2003) (hereafter H03 and EH03, respec-

Corresponding author: Naoko Kitabatake, Meteorological Research Institute, 1-1 Nagamine, Tsukuba 305-0052, Japan. E-mail: nkitabat@mri-jma.go.jp. (02008, the Meteorological Society of Japan.

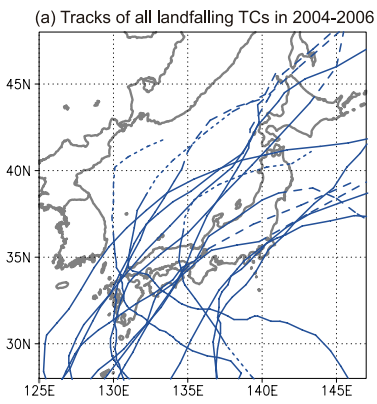

(b) Landfalling TCs of "tropical" structure

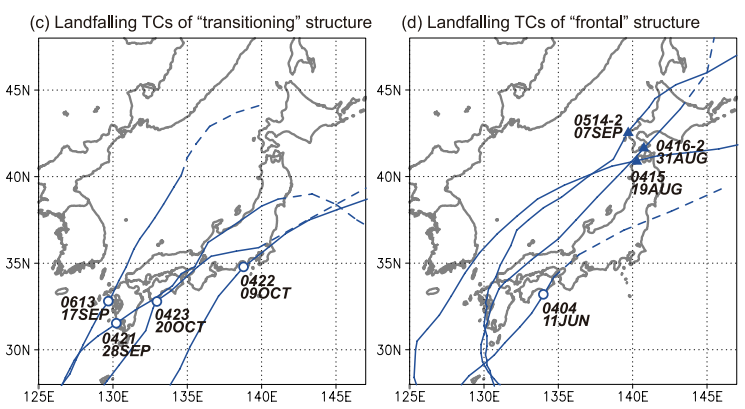

Fig. 1. (a) Tracks of $15 \mathrm{TCs}$ that made landfall in the main islands of Japan during 2004-2006. Solid, dotted, and dashed lines indicate the track of a TC with max wind speed $>17.2$ $\mathrm{m} \mathrm{s}^{-1}$, a tropical depression, and an extratropical low, respectively. (b) Same as (a) but for TCs of the "typical tropical cyclone" structure at the time of landfall (see text and Fig. 2). Each landfall place is labeled with TC number and date of landfall. (c) (d) Same as (b) but for "transitioning cyclone" and "frontal cyclone", respectively.

tively). Some significant features associated with the landfalling TCs will be discussed with regard to the cyclone phase diagram, based on a hypothesis that the variety of the landfalling TCs is related to ET.

\section{Data, definitions, and method}

The parametric information on TCs including their center positions and intensities is based on the best track data basically at 6-hour intervals created by the Japan Meteorological Agency (JMA). The time at which a TC made landfall in the main islands of Japan is also designated by the JMA.

The Japanese 25-year Reanalysis (JRA-25: 19792004) and the JMA Climate Data Assimilation System (JCDAS: $2005^{-}$) datasets at $1.25^{\circ} \times 1.25^{\circ}$ resolution of 6 hour intervals (Onogi et al. 2007) are used for calculation of parameters that represent the structure of a cyclone. A bogus vortex based on the method of Fiorino (2002) is implemented for each TC in the reanalysis (Hatsushika et al. 2006; Onogi et al. 2007).

H03 defined parameters that represent the structure of a TC and plotted them in a cyclone phase space (CPS). Parameter $B$ is defined as storm- motion-relative 900$600 \mathrm{hPa}$ thickness asymmetry across the cyclone within $500 \mathrm{~km}$ radius, which represents frontal nature. Parameter $-V_{T}^{L}$ is defined as vertical derivative of horizontal height gradient in 900-600 hPa layer, which 
represents the cold- versus warm-core structure. Thus, it is presumed that a tropical cyclone has a structure represented by a small value of $B$ and a large value of $-V_{T}^{L}$, and that an extratropical cyclone has a structure represented by a large value of $B$ and a small value of $-V_{T}^{L}$. EH03 define the ET onset and completion as $B>10$ and $-V_{T}^{L}<0$, respectively.

We use the gridded data at $925 \mathrm{hPa}$ and $600 \mathrm{hPa}$ levels to determine the parameters in this study, particularly simplifying the calculation of $-V_{T}^{L}$. The 925 $\mathrm{hPa}$ level is selected for convenience of use of the reanalysis datasets. Central position of a TC and its translation direction/speed are extracted from the JMA best track data. We apply the thresholds of $B=10$ and $-V_{T}^{L}=0$ defined by EH03 to a cyclone phase diagram in this study as depicted in Fig. 2, and define a cyclone in the lower-right, upper-right, and upper-left quadrant of the diagram as that of the structure of a "typical tropical cyclone", a "transitioning cyclone", and a "frontal cyclone", respectively.

\section{Results}

3.1 Cyclone phases of landfalling TCs during 2004-2006

Figure 2 presents cyclone phases of TCs landfalling in Japan during 2004-2006, calculated by using the data just before the landfall. For example, data for 0000 UTC October 20, 2004 in the JRA-25 dataset at 6-hour intervals were used for TY Tokage (0423) that made landfall at 0400 UTC. TY Chaba (0416) and TY Nabi (0514) made second landfall in northern Japan after their first landfall in western Japan, and consequently 17 landfall cases of 15 TCs are depicted in Fig. 2.

Nine cases including the first landfall of the above Chaba (0416) and Nabi (0514) are found in the lowerright quadrant of Fig. 2, suggesting the typical TC structures. The tracks of these 9 TCs are depicted in Fig. $1 \mathrm{~b}$, indicating that these 9 TCs made landfall in western and eastern Japan Islands from June 21 through September 10, including mid-summer. It is likely that a TC landfalling in Japan south of $40^{\circ} \mathrm{N}$ in summer has the structure of a typical tropical cyclone, since the environmental baroclinicity would be weak. Three TCs (TY Namtheun (0410), TS Malou (0411), and STS Wukong (0610)) were moving northwestward at the period of their landfall, and most of the other TCs in this category seems to have been at the stage just after the recurvature (Fig. 1b). These are consistent with the fact that these storms are classified as the typical TC structure.

Four cases including the second landfalls of Chaba (0416) and Nabi (0514) are found in the upper-left quadrant in Fig. 2 that suggests the structure of a frontal cyclone. The northeastward movements of these 4 TCs in Fig. 1d are consistent with the nature of the frontal cyclone. One of them (TY Conson (0404)) made landfall in western Japan on June 11, and the other 3 TCs made landfall in northern Japan in August or September (Fig. 1d). Climatologically the environmental baroclinicity depends on the seasons and the latitudes; the strongly baroclinic environment in the very early period of the TC season or in higher latitudes results in the structure of these TCs.

The other 4 cases are found in the upper-right quadrant in Fig. 2, suggesting that the TCs were undergoing ET with a warm-core asymmetric structure. These TCs moved northeastward and made landfall in western and eastern Japan after September 11 (Fig. 1c), causing significant damage to Japan. TY Meari (0421) and TY Tokage (0423) caused heavy rainfall in wide regions along the autumnal stationary front that often forms along the Japan Islands; TY Ma-on (0422) and TY Shanshan (0613) were accompanied by localized gusts or tornados. These suggest that precautions should be taken against a TC approaching Japan in mid- and late

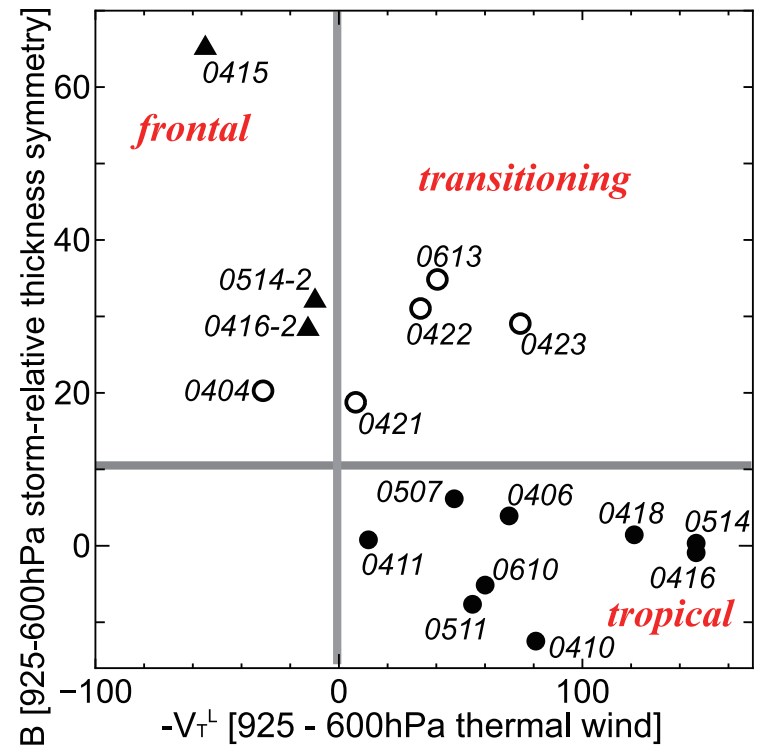

Fig. 2. Cyclone phase diagram of 15 TCs just before their landfall in the main islands of Japan. Dot denotes a TC landfalling south of $40^{\circ} \mathrm{N}$ from Jun 21 through Sep 10 including midsummer. Open circle is for a TC landfalling south of $40^{\circ} \mathrm{N}$ before Jun 20 or after Sep 11. Triangle is for a TC landfalling in northern Japan north of $40^{\circ} \mathrm{N}$. Each mark is labeled with TC number; " -2 " indicates a second landfall of a TC.

autumn since it may be associated with features different from those of a typical TC.

\subsection{Case examples}

Figure $3 \mathrm{a}$ presents the cyclone phase evolution of TY Songda (0418) that brought strong winds to much of the Japan Islands. The value of $B$ was nearly 0 and $-V_{T}^{L}$ was smaller than 100 at the early stage of its life cycle; $-V_{T}^{L}$ increased in magnitude until 1200 UTC 5 September when Songda began decreasing its intensity (according to the JMA best track). The phase evolution suggests that Songda began ET at about 0600 UTC 7 September and completed it between 1200 UTC and 1800 UTC, i.e., Songda was a transitioning system during 0600 UTC to 1800 UTC. Songda obtained a warm-core structure again at 0600 to 1800 UTC 8 September at the reintensification stage. This phase evolution in Fig. 3a is primarily consistent with the structural change described by Kitabatake et al. (2007).

Figure $3 \mathrm{~b}$ depicts lower-tropospheric thermal gradients just before the landfall of Songda in western Japan. Songda was moving northeastward more than $500 \mathrm{~km}$ south of the primary baroclinic zone that was present over the Sea of Japan and the northern Korean Peninsula. Thus the value of $B$ was still small at the period of the landfall, while the value of $-V_{T}^{L}$ was very large; therefore Songda had a typical tropical cyclone structure.

Figures 3c and d present TY Tokage (0423) that made landfall in western Japan on October 20, 2004 with the transitioning cyclone structure, and caused heavy rainfall (accumulated precipitation of 300-400 $\mathrm{mm}$ in a period of $24 \mathrm{hr}$ ) along with the resultant floods to a wide region of western Japan (JMA06; MRI06), i.e., on the left side of the storm track. Tokage was moving along the southern periphery of a strong baroclinic zone over the Japan Islands in Fig. 3d, which resulted in a large value of $B$ during the passage of the Japan Islands as shown in Fig. 3c. A relatively large value of $-V_{T}^{L}$ in Fig. 3c indicates strong cyclonic winds in the lower troposphere associated with the warm-core structure. Atallah et al. (2007) pointed out in their study of Atlantic hurricanes that precipitation on the left side of 


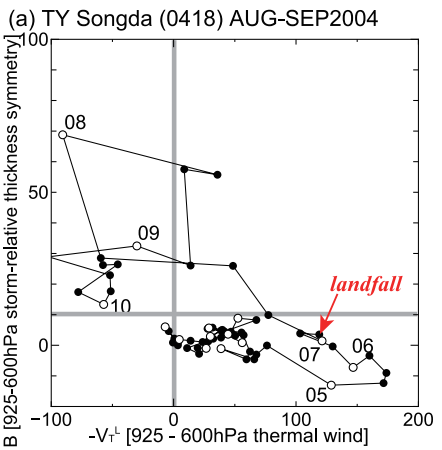

(b) 0000UTC07SEP2004

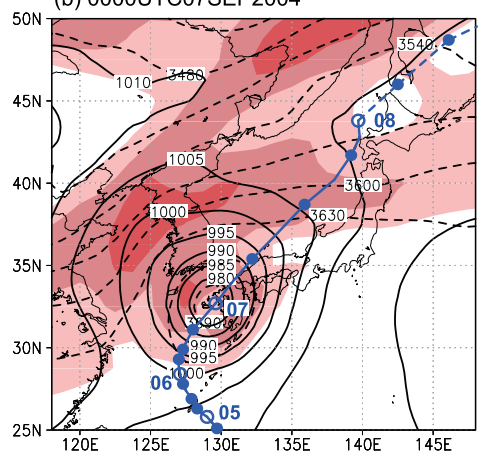

(c) TY Tokage (0423) OCT2004

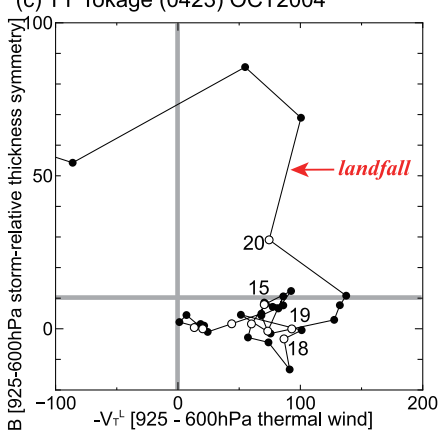

(d) 0000UTC200CT2004

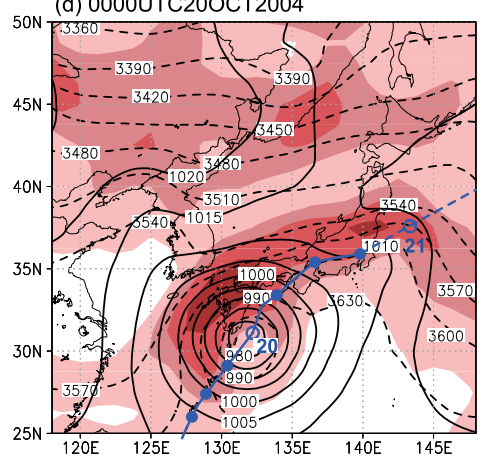

(e) TY Nabi (0514) AUG-SEP2005

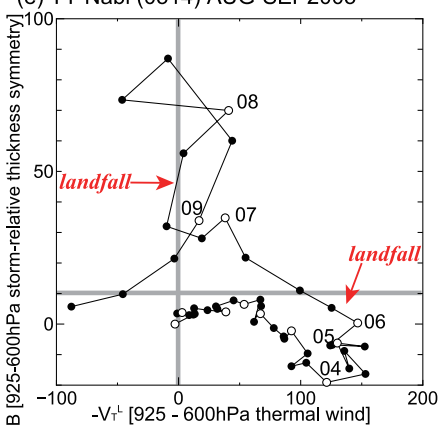

(f) 0000UTC06SEP2005

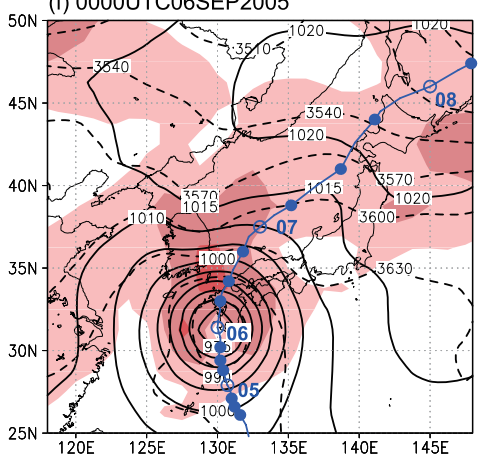

Fig. 3. (a) Cyclone phase evolution of TY Songda (0418) from 26 Aug trough 10 Sep 2004. Phase for 0000 UTC is marked by an open circle and phase for 0600,1200, and 1800 UTC by a dot. Selected open circles are labeled with the day. (b) Sea level pressure (hPa, solid), 925-600 hPa thickness (m, dashed) and its horizontal gradient (color, at intervals of $\left.60 \mathrm{~m}(1000 \mathrm{~km})^{-1}\right)$ at 0000 UTC 07 Sep 2004. Track of TY Songda (0418) is also depicted with blue line (see also Fig. 1). (c) Same as (a) but for TY Tokage (0423) from 12 through 20 Oct 2004. (d) Same as (b) but for 0000 UTC 20 Oct 2004 with the track of TY Tokage. (e) Same as (a) but for TY Nabi (0514) from 29 Aug through 09 Sep 2005. (f) Same as (b) but for 0000 UTC 06 Sep 2005 with the track of TY Nabi.

the storm track is characteristic of a TC undergoing ET. Thus the large values of $B$ and $-V_{T}^{L}$ may have been related to the heavy rainfall associated with Tokage. JMA06 also suggested the relation between the asymmetry of Tokage and the associated rainfall. In addition, Tokage was associated with northerly gusts west of the cyclone center, similar to TY Ma-on (0422) that is another transitioning cyclone in the upper-right quadrant of Fig. 2 (see also Fig. 1c). Mashiko (2005) showed that the gust associated with Ma-on resulted from strong baroclinicity as well as the lowertropospheric strong cyclonic circulation due to the original TC.

Figures $3 e$ and f present TY Nabi (0514) that made its first landfall in western Japan in early September in 2005 along a track similar to TY Songda in 2004 (see the track of Songda in Fig. 3b and Fig. 1b). The cyclone phase of Nabi (Fig. 3e) at about the time of its first landfall in western Japan was also similar to Songda $\left(B \approx 0\right.$ and $\left.-V_{T}^{L}>100\right)$ (see also Fig. 2). However, satellite imagery (not shown) indicates that TY Nabi was associated with a significant frontal cloud band extending from north of cyclone center toward northern Japan (figure not shown) along the baroclinic zone in Fig. 3f, and heavy rainfall was observed on the forward (i.e., northern) side of the northward-moving TC with extreme accumulated precipitation of $600-800 \mathrm{~mm}$ in $24 \mathrm{hr}$ in western Japan. In Fig. 3f large thickness gradients are present just north of the cyclone center, which is likely to contribute to the frontal rainfall. The moving direction of TY Nabi was nearly at right angles to the frontal zone over western Japan; thus the storm-motionrelative thermal asymmetry $B$ is very small in spite of the large thickness gradients. Nabi moved northeastward in the baroclinic zone over the Sea of Japan after crossing western Japan, and made second landfall in northern Japan with the frontal cyclone structure $(B \gg$
10 and $\left.-V_{T}^{L}<0\right)$.

\section{Discussion}

A TC that has the structure of a frontal cyclone or a transitioning cyclone with a large value of $B$ is likely to be associated with frontal rainfall that may be intensified by the strong cyclonic circulation in the lower troposphere. In contrast, a TC with $B<10$ and $-V_{T}^{L}>0$ is defined as a storm of the typical tropical cyclone structure, presumed to have a symmetric structure. However, as shown in TY Nabi's case, when a TC is moving at a large angle to a frontal zone, the parameter $B$ of the TC can be small in spite of large thermal gradients. Figure 4 presents a comparison of the parameter $B$ with the magnitude of the horizontal gradient of $925-600 \mathrm{hPa}$ thickness $\left(|\nabla(\Delta Z)|, \mathrm{m} \cdot(1000 \mathrm{~km})^{-1}\right)$ averaged within 500 $\mathrm{km}$ radius of a landfalling TC. In terms of all of 17 landfall cases during 2004-2006, B correlates closely with $|\nabla(\Delta Z)|$ (blue line in Fig. 4). However, in terms of 9 cases with the structure of a typical tropical cyclone $(B$ $<10), B$ correlates very poorly with $|\nabla(\Delta Z)|$ as indicated by a red line in Fig. 4 . These 9 cases are associated with rather small thickness gradients $(|\nabla(\Delta Z)|<40)$. These suggest that a TC moves along a baroclinic zone in a strongly baroclinic environment $(|\nabla(\Delta Z)|>40)$, but often moves unrelated to the direction of a baroclinic zone in a weakly baroclinic environment $(|\nabla(\Delta Z)|<40)$. In addition, Fig. 4 may imply to support the threshold of $B=10$ as the beginning of ET.

TY Nabi $(0514)$ is at $B \approx 0$ and $|\nabla(\Delta Z)| \approx 30$ in Fig. 4, whereas TY Songda (0418) is at $B \approx 0$ and $|\nabla(\Delta Z)| \approx 15$. As shown in the previous section, Nabi and Songda appear to have similar structures in Fig. 2, but Fig. 4 reveals that Nabi is associated with larger thermal gradients than Songda, which reflect the difference of the 


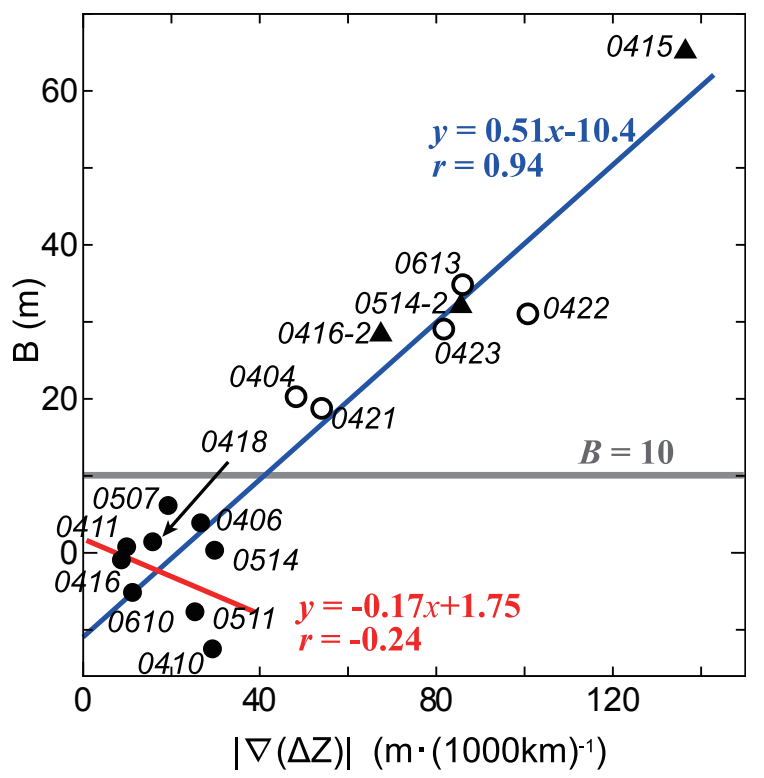

Fig. 4. Relationship between the mean horizontal thickness gradient of a landfalling TC ( $x$-axis) and its parameter $B(y$ axis). Blue line indicates the linear regression of 17 landfall cases, and red indicates that of 9 cases for $B<10$.

thermal fields shown in Figs. 3f and $3 \mathrm{~b}$. This difference in thermal gradients may result in the frontal heavy rainfall in Nabi's case in spite of the small value of B.

The thermal gradient of Nabi is comparable to that of TY Namtheun (0410) in Fig. 4 that made landfall in western Japan (Fig. 1b) in midsummer. Nevertheless Namtheun was not associated with frontal cloud bands in satellite imagery as well as the lower-tropospheric baroclinicity (MRI06), and its negative value of $B(<-10$ in Figs. 2 and 4) is a contrast to that of a normal extratropical low. A negative value of $B$ is common to the TCs just before their recurvature as shown in Fig. 3. Thus the thermal gradient $|\nabla(\Delta Z)|$ may poorly represent possible frontal nature only in case of $B<0$. In addition, when Namtheun made landfall, extreme precipitation exceeding $1300 \mathrm{~mm}$ in $24 \mathrm{hr}$ was observed on the right side of the storm track (JMA06; MRI06), which is characteristic of a TC before the "precipitation shift" (Atallah et al. 2007) that is likely to be related to the increase of $B$. Further study is needed to clarify the structure of a TC with negative $B$ as well as ET.

\section{Summary}

The cyclone phases of TCs that made landfall in Japan during 2004-2006 were examined by using the gridded reanalysis datasets of the JMA, i.e., JRA-25 and JCDAS, for the purpose of discussing their structure associated with significant features. Seventeen landfall cases of 15 TCs were diagnosed. TCs with 9 landfalls south of $40^{\circ} \mathrm{N}$ from late June through early September had the structure of typical tropical cyclone, i.e., a thermally symmetric warm-core structure. TCs of 3 landfallings north of $40^{\circ} \mathrm{N}$ and one landfalling in western Japan in mid-June had structures of a frontal cyclone, which suggests that the environmental baroclinicity would have contributed to the structure change of the cyclones. With the other 4 landfalls south of $40^{\circ} \mathrm{N}$ after mid-September, TCs were transitioning into extratropical cyclones with thermally asymmetric warm-core structures, and were associated with significant features including heavy rainfall and localized gusts that are considered to be related to the frontal nature of the transitioning cyclones. These findings suggest that the structure of a TC may depend on the season and the latitude of its landfall, which is consistent with the results of Hart and Evans (2001) for the Atlantic storms. It is also suggested that the cyclone phase diagram may imply possible significant features associated with a TC. The value of the parameter $B$, i.e., the storm-motionrelative thermal asymmetry, was very small in spite of the thermal gradients when a TC moved at a large angle to the environmental baroclinic zone before the beginning of the ET, which may be associated with heavy frontal rainfall due to the TC-front interaction.

\section{Acknowledgements}

The authors are grateful to Ryouta Sakai of the JMA for helpful comments.

\section{Comments and supplements}

1. A list of TCs landfalling in Japan during 2004-2006 is shown in the supplement.

\section{References}

Atallah, E., L. F. Bosart, and A. R. Aiyyer, 2007: Precipitation distribution associated with landfalling tropical cyclones over the eastern United States. Mon. Wea. Rev., 135, 21852206.

Evans, J. L., and R. E. Hart, 2003: Objective indicators of the life cycle evolution of extratropical transition for Atlantic tropical cyclones. Mon. Wea. Rev., 131, 909-925.

Fiorino, M., 2002: Analysis and forecasts of tropical cyclones in the ECMWF 40-year reanalysis (ERA-40). Preprints of the 25th Conference on Hurricanes and Tropical Meteorology, San Diego, CA, Amer. Meteor. Soc., 41-42.

Hatsushika, H., J. Tsutsui, M. Fiorino, and K. Onogi, 2006: Impact of wind profile retrievals on the analysis of tropical cyclones in the JRA-25 reanalysis. J. Meteor. Soc. Japan, 84, 891-905.

Hart, R. E., 2003: A cyclone phase space derived from thermal wind and thermal asymmetry. Mon. Wea. Rev., 131, 585616.

Hart, R. E., and J. L. Evans, 2001: A climatology of the extratropical transition of Atlantic tropical cyclones. $J$. Climate, 14, 546-564.

Japan Meteorological Agency, 2006: Heavy rainfalls during the baiu period and remarkable typhoons in 2004. Thech. Rep. of Japan Meteorological Agency, 129, 281 pp (in Japanese).

Kitabatake, N., S. Hoshino, K. Bessho, and F. Fujibe, 2007: Structure and intensity change of Typhoon Songda (0418) undergoing extratropical transition. Pap. Meteor. Geophys., 58, 135-153.

Klein, P. M., P. A. Harr, and R. L. Elsberry, 2000: Extratropical transition of western North Pacific tropical cyclones: An overview and conceptual model of the transformation stage. Wea. Forecasting, 15, 373-396.

Mashiko, W., 2005: Generation mechanism of strong winds observed during the passage of Typhoon Ma-on (2004) in the southern part of Kanto plain occupied by cold air at the low-level. Kaiyo Gogai, 42, 145-152 (in Japanese).

Muramatsu, T., 1985: A study on the changes of the threedimensional structure and the movement speed of the typhoon through its lifetime. Tech. Rep. of the Meteorological Research Institute, 14, $117 \mathrm{pp}$ (in Japanese, available from http://www.mri-jma.go.jp/).

Onogi, K., J. Tsutsui, H. Koide, M. Sakamoto, S. Kobayashi, H. Hatsushika, T. Matsumoto, N. Yamazaki, H. Kamahori, K. Takahashi, S. Kadokura, K. Wada, K. Kato, R. Oyama, T. Ose, N. Mannoji, and R. Taira, 2007: The JRA-25 Reanalysis. J. Meteor. Soc. Japan, 85, 369-432.

Typhoon Research Department/ Meteorological Research Institute, 2006: Summary of Typhoons Landfalling on Japan in 2004. Tech. Rep. of the Meteorological Research Institute, 49, $36 \mathrm{pp}$ (in Japanese, available from http:// www.mri-jma.go.jp/).

Manuscript received 29 November 2007, accepted 16 February 2008 SOLA: http://www.jstage.jst.go.jp/browse/sola/ 